\title{
Optimization of process parameters and kinetics of adsorption treatment of thallium-containing wastewater
}

\author{
Tao Wen ${ }^{1}$, Yuanyuan $\mathrm{Zhao}^{2 *}$, Youze $\mathrm{Xu}^{2 *}$, Jing $\mathrm{Guo}^{3}$, Guangyi $\mathrm{Fu}^{2}$, Yingxiang Cheng ${ }^{2}$, Yu Zhong ${ }^{2}$ \\ 1. College of Chemistry and Chemical Engineering, Hunan Provincial Key Laboratory of Efficient and Clean Utilization of Manganese \\ Resources, Central South University, Changsha 410083, Hunan, China \\ ${ }^{2}$. Key Laboratory of Water Pollution Control Technology, Hunan Research Academy of Environmental Science, Changsha Hunan \\ 410000; \\ ${ }^{3}$. Hunan Dongting Lake Ecological Environment Observation Center, Yueyang, 414000
}

\begin{abstract}
Thallium is an extremely toxic metal and abundant in industrial wastewater but little studied. In order to understand the optimal adsorption kinetic parameters of the chelating resin containing hydrazine wastewater, we carried out adsorption experiments on the cerium-containing wastewater treated by chemical precipitation. In this chapter, the optimum adsorption conditions, adsorption model, dynamic adsorption curve and desorption and regeneration of adsorbent were determined at different $\mathrm{pH}$, temperature, adsorption time and different adsorbent dosage. The results show that the removal rate of thallium wastewater by resin is up to $97.5 \%$ when the $\mathrm{pH}$ value is 9 . The optimum adsorption temperature is 30 and the adsorption reached equilibrium at $80 \mathrm{~min}$. The adsorption process is consistent with Lagergren quasi-second-order adsorption and Langmuir isotherm model. The regenerative properties of the resin show that the resin adsorption rates still reach $95.8 \%$ after repeat use for six times. In summary, the chelating resin has good adsorption and reusability to the thallium-containing wastewater
\end{abstract}

\section{Introduction}

With the development of modern society inevitably produced various types of contaminants, such as organic compounds[1, 2], dyes[3-5], and heavy metals[6-8], which have caused widely concern for water pollution because of their acute toxicity, non-degradability and bioaccumulation. Thallium (Tl) is a rare heavy metal element with high toxicity[9-11], which is more toxic than lead, mercury, etc., and is equivalent to the toxicity of arsenic[12]. Tl is one of the priority pollutants listed in US Environmental Protection Agency as it has caused many accidents and occupational poisoning[13]. With the development of socials and the progress of industrial technology, $\mathrm{Tl}$ and its compounds have found an increasingly wide utilization in ore exploration, semiconductors, catalysis, etc.[14-17]. The pollution situation of $\mathrm{Tl}$ metal in the water environment is increasing year by year. If not treat in time, Tl metal will seriously threaten the water environment and human health[18]. The problem of $\mathrm{Tl}$ metal pollution has been increasingly valued by human beings.

At present, the main technologies for the treatment of Tl-containing wastewater have oxidation flocculation, chemical precipitation technique, ion exchange technique, solution extraction method, adsorption, etc. Adsorption is one of the most widely used methods. Other methods are basically in the phase of theoretical research, and there are few successful application examples[19]. Karatepe et al[20] used Chromosorb 105 resin to selectively adsorb the complexes of $\mathrm{Tl}$ contain chloride and iodine, but the enrichment effect of the technology was not ideal. Amin et al[21] fixed the $\mathrm{Tl}$ on the styrene divinylbenzene anion exchange resin, then measured the absorbance of $\mathrm{Tl}$ at 636 $\mathrm{nm}$ and $830 \mathrm{~nm}$. The method has been successfully application to test $\mathrm{Tl}$ in water. Luo et al[22] used tributyl phosphate leaching resin as a column packing to separate the enriched water and $\mathrm{Tl}$ in wastewater. The research showed that in 5\% (volume fraction) hydrochloric acidnitric acid $(1+3)$ solution, tributyl phosphate leaching resin could quantitative adsorption of trace $\mathrm{Tl}$ in water, rapid desorption with $2 \mathrm{~g} / \mathrm{L}$ sulfurous acid and $2 \mathrm{~g} / \mathrm{L}$ ascorbic acid as desorbent, the recovery rate is between $96 \%$ and $102 \%$. For industrial Tl-containing wastewater in our country, it is usually treated by chemical precipitation, but the post-treatment concentration is difficult to meet national standards. The limit value of $\mathrm{Tl}$ in environmental quality standards for surface water (GB $3838-2002$ ) promulgated by China in 2002 is $0.0004 \mathrm{mg} / \mathrm{L}$, the value of $\mathrm{Tl}$ is much lower than that of arsenic, lead, chromium and mercury[23]. Therefore, industrial wastewater needs to be treated in depth. In view of such refractory Tl-containing wastewater, the study is based on the existing advanced treatment process for Tl-containing wastewater. We need to find the optimal conditions for the adsorption of $\mathrm{Tl}$ by existing materials, and conducting adsorption kinetics research to optimize its process parameters.

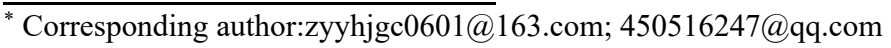




\section{Experimental}

\subsection{Materials and reagents}

Activated alumina (Tianjin Sailboat Chemical Reagent Technology Co., Ltd.), Chelating resin (Hunan Changsha Yuchi Chemical Co., Ltd.), Molecular sieve (Tianjin Kemiou Chemical Reagent Co., Ltd.)

The experimental wastewater was taken from the raw water and the secondary sedimentation tank effluent of the sewage treatment station of a zinc material co., Ltd. in Zhuzhou City, Hunan Province. The main pollutant of experimental wastewater was $\mathrm{Tl}$, the concentration of $\mathrm{Tl}$ in the raw water was about $10 \mathrm{mg} / \mathrm{L}$, and the concentration of $\mathrm{Tl}$ in the effluent of the second settling tank was about $10 \sim 30 \mu \mathrm{g} / \mathrm{L}$. All drugs were analytical reagent.

\subsection{Characterization and analysis}

Determination of $\mathrm{Tl}$ in wastewater by ICP Mass Spectrometer

\subsection{Adsorption experiments}

In this thesis, Tl-containing wastewater was used as a target pollutant to study the adsorption performance and optimization of process parameters of chelating resin. A series of adsorption experiments were carried out by adding a certain amount of chelating resin $(5 \mathrm{~g})$ into 100 $\mathrm{mL}$ Tl-containing wastewater in a shaker $(12 \mathrm{~h})$ at $30^{\circ} \mathrm{C}$. The influence of Tl-containing wastewater $\mathrm{pH}$ on the adsorption was carried out from $\mathrm{pH} 6.0$ to 11.0. The adsorption experiments had been determined at different temperatures $\left(20,25,30,35,40,45\right.$ and $\left.50^{\circ} \mathrm{C}\right)$. The instantaneous equilibrium concentration of the filtrate was determined at different adsorption periods $(10,20, .30,40$, $50,60,70,80,90$ and $100 \mathrm{~min})$. The influence of initial Tl-containing wastewater concentration on the adsorption was carried out.

\subsection{Desorption experiments}

After adsorption, the chelating resin was washed three times with distilled water and dried, then desorption with a certain concentration of hydrochloric acid. Determined the concentration of $\mathrm{Tl}$ in the desorbed solution and calculated the desorption. The chelating resin can be reused in adsorption tests.

\subsection{Dynamic adsorption}

Weighing a certain amount of chelating resin into the adsorption column and wetting it with ultrapure water. Continuously adding wastewater to the adsorption column with a constant flow rate at room temperature $\left(25^{\circ} \mathrm{C}\right)$. Then, at intervals, the solution penetrating the chelating resin was collected and detected until the concentration of $\mathrm{Tl}$ in the effluent was the same as the concentration of $\mathrm{Tl}$ in the original solution. At this point, the dynamic adsorption had reached saturation. The model diagram is as follows:

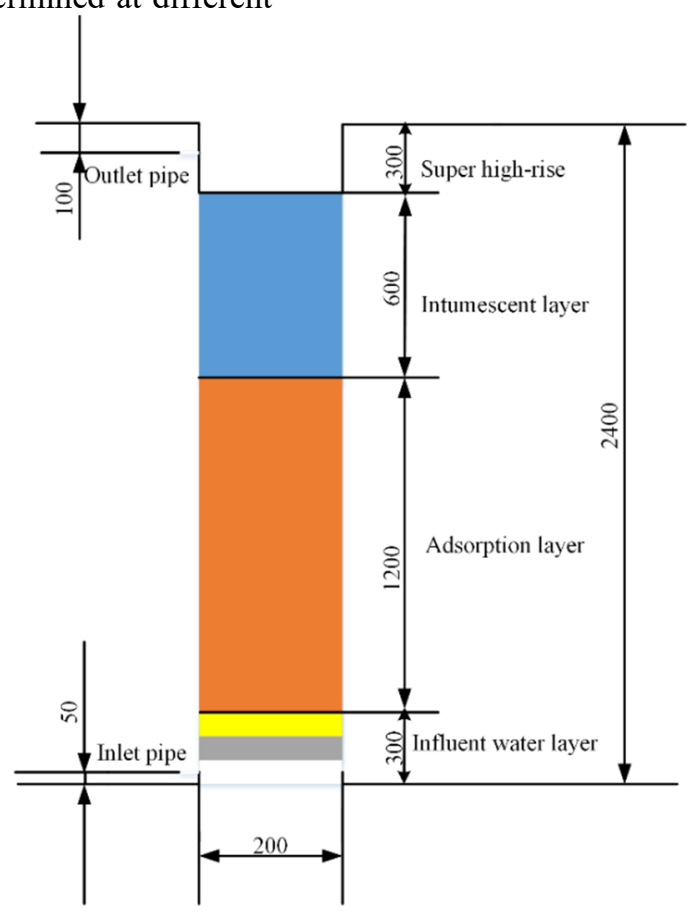

Fig.1 Model diagram 


\section{Results and discussion}

\subsection{Adsorption tests}

\subsubsection{Effect of $p H$}

The adsorption tests on chelating resin were conducted in different $\mathrm{pH}$ range from 6.0 to 11.0 , and the results were shown in Fig. 2. As we known, different metals have different optimum $\mathrm{pH}$ values of adsorption[24]. The values of $\mathrm{pH}$ not only affects the surface charges and state of the functional groups on the surface of adsorbents, but also affects the species of metal ions in solution[25, 26].The values of $\mathrm{pH}$ has a great influence on the adsorption performance of the adsorbent. From the Fig. 2, we can know that at relatively low $\mathrm{pH}$ values of 6.0 and 9.0 , the removal efficiency of $\mathrm{Tl}$ in water samples is below $90 \%$. When the values of $\mathrm{pH}$ increased from 9.0 to 9.5 , the

removal efficiency of $\mathrm{Tl}$ is up to about $97.5 \%$. However, the removal efficiency of $\mathrm{Tl}$ has decreased at the $\mathrm{pH}$ values greater than 9.5. The phenomenon indicates that the greater the acidity of the wastewater, the $\mathrm{Tl}$ on adsorbent will compete with the $\mathrm{H}^{+}$in the water to reduce the adsorption capacity of the resin on the Tl. As the $\mathrm{pH}$ increased, the acid effect coefficient gradually decreases, which is more favorable for the adsorption of the resin to the $\mathrm{Tl}$. At a higher $\mathrm{pH}$, the hydrolysis reaction of $\mathrm{Al}^{3+}$ and $\mathrm{Fe}^{3+}$ in the wastewater will produce precipitation, which effect the adsorption capacity of the resin. So chelating resin can be used at a $\mathrm{pH}$ values about 9.0 for treating Tlcontaining wastewater. The following experiments were all carried out under the conditions of $\mathrm{pH}=9.0$.

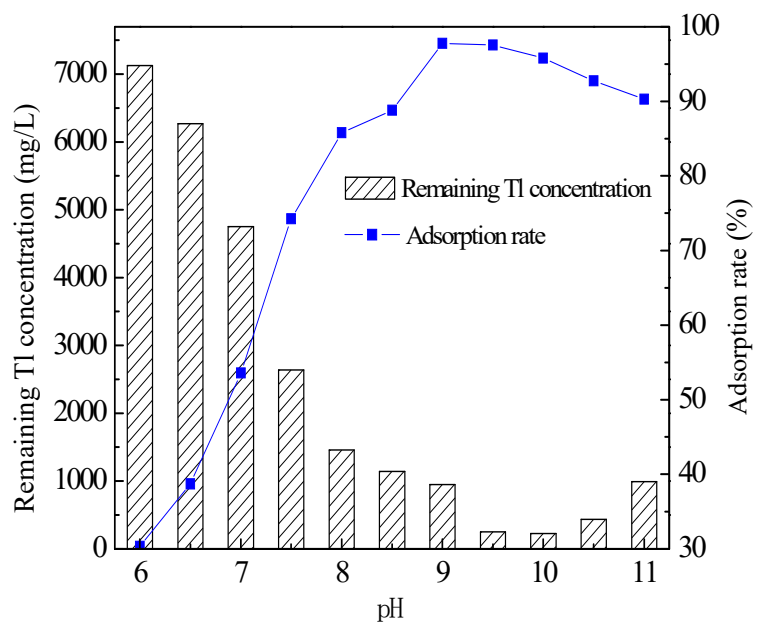

Fig.2 Effect of wastewater $\mathrm{pH}$ on adsorption of $\mathrm{Tl}$ by chelating resin $(5 \mathrm{~g})$ at $30^{\circ} \mathrm{C}$

\subsubsection{Effect of temperature}

In this paper, the adsorption effect of chelating resin on $\mathrm{Tl}$ in wastewater was tested at different temperature, the results were shown in Fig. 3. The adsorption efficiency of resin to $\mathrm{Tl}$ increased with increasing temperature from $20^{\circ} \mathrm{C}$ to $30^{\circ} \mathrm{C}$. Results indicated that the adsorption process was difficult to reach equilibrium quickly at a lower temperature. The increase in adsorption capacities of the adsorbent at higher temperature may be attributed to the enlargement of pore size or specific surface area[27]. When further increasing temperature to $50^{\circ} \mathrm{C}$, the adsorption efficiency instead to decreased. This indicates that the adsorption may be an exothermic process. The adsorption capacity of the resin decreases as increasing the temperature after reaching the adsorption equilibrium. Fig. 3 displays that the optimum temperature for the adsorption of resin on $\mathrm{Tl}$ is $30^{\circ} \mathrm{C}$. 


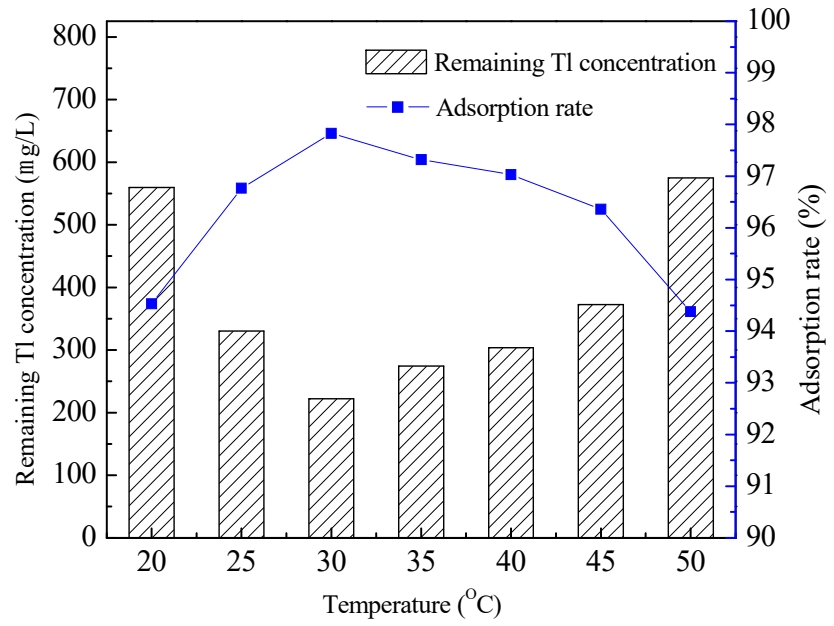

Fig. 3 Effect of temperature on adsorption of $\mathrm{Tl}$ by chelating resin $(5 \mathrm{~g})$

\subsubsection{Adsorption kinetics}

The effect of contact time on the adsorption efficiency of $\mathrm{Tl}$ was investigated with the contact time from 0 to 100 min. It is obvious that the adsorption rate of $\mathrm{Tl}$ by chelating resin is very rapid and the adsorption reaches equilibrium within $80 \mathrm{~min}$ (Fig. 4). The amount of adsorption on $\mathrm{Tl}$ increases dramatically at a lower contact time. The adsorption process of resin on heavy metal ions in wastewater is a liquid-solid adsorption process.

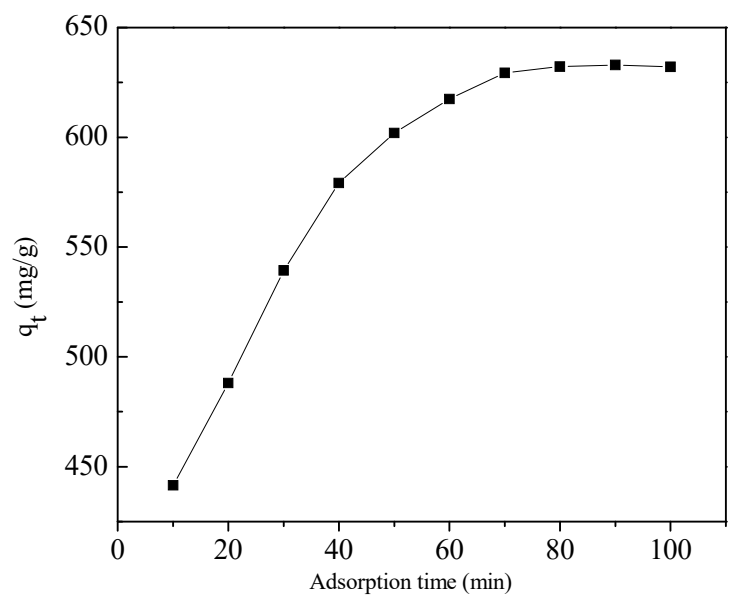

Fig. 4 Effect of adsorption time on adsorption capacity

In order to study the mechanism of liquid-solid adsorption, our experiments propose two kinetic models (Lagergren quasi-first-order kinetic models and Lagergren quasi-second-order kinetic models), the equations of the kinetic models abovementioned are described as follows [28-30]:

Lagergren quasi-first-order kinetic models

$$
\ln \left(q_{e}-q_{t}\right)=\ln \left(q_{e}\right)-K_{1} t
$$

Lagergren quasi-second-order kinetic models

$$
\frac{t}{q_{t}}=\frac{1}{K_{2} q_{e}^{2}}+\frac{1}{q_{e}}
$$

Where, $q_{e}$ is the amount of adsorption $(\mu \mathrm{g} / \mathrm{g})$ at the equilibrium of adsorption. $q_{t}$ is the amount of adsorption $(\mu \mathrm{g} / \mathrm{g})$ at any instant of time $\mathrm{t}(\mathrm{min}) K_{1}\left(\mathrm{~min}^{-1}\right)$ and $K_{2}$ $(\mathrm{g} /(\mu \mathrm{g} \cdot \mathrm{min})$ are the rate constant of Lagergren quasi-firstorder adsorption and Lagergren quasi-second-order adsorption, respectively.
Linear regression fitting was performed on the two kinetic models according to experimental data. The results were shown in Fig. 5 and equation are displayed below[31, 32]:

Lagergren quasi-first-order kinetic models

$$
\ln \left(q_{e}-q_{t}\right)=6.655-0.07659 \mathrm{t}
$$$$
\mathrm{R}^{2}=0.9498
$$

Lagergren quasi-second-order kinetic models

$$
\begin{aligned}
& \frac{t}{q_{t}}=0.00988+0.00147 \\
& \mathrm{R}^{2}=0.9996
\end{aligned}
$$

We can see from Fig. 5 that the resin adsorption progress has a good linear regression effect on both kinetic models. According to the fitting results of the above two models, the process of resin adsorption is more in line with Lagergren quasi-second-order kinetic model according to the comparison of correlation coefficients $\left(\mathrm{R}^{2}\right)$. From the 
result, the adsorption progress of $\mathrm{Tl}$ onto the absorbents proceeded by chemisorption mechanism[33].

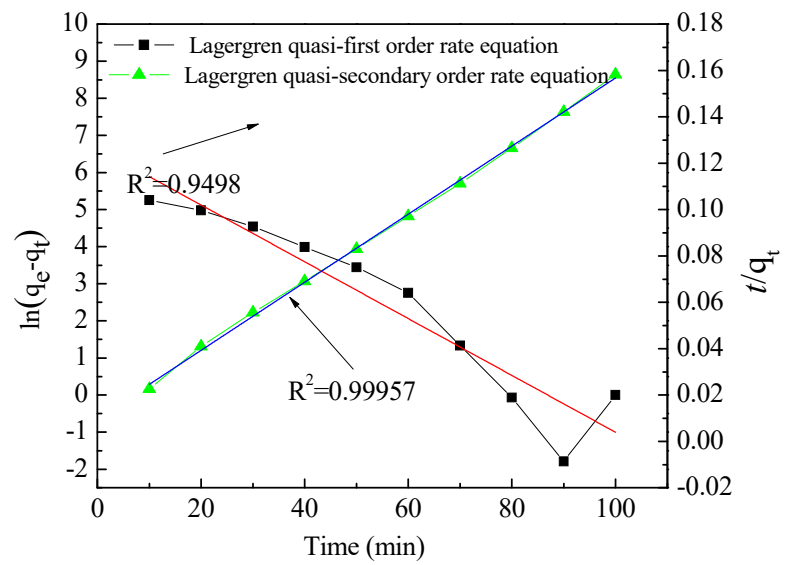

Fig. 5 Linear fitting of Lagergren kinetic models

\subsubsection{Adsorption isotherm}

In order to study the adsorption isotherms of $\mathrm{Tl}$ on resin, the adsorption of $\mathrm{Tl}$ at different initial concentrations was studied. Results were shown in Fig. 6. In this study, two common adsorption isotherm models (Langmuir and Freundlich models) were used to investigate the interaction of $\mathrm{Tl}$ and surface of adsorbent by the test data at adsorption equilibrium.

Langmuir adsorption isotherm model

Langmuir isotherm is based on the assumption that the adsorption sites on the adsorbent surface are limited and evenly distributed. The equation is displayed as follows[31, 34]:

$$
\frac{c_{e}}{q_{e}}=\frac{1}{q_{0} b}+\frac{c_{e}}{q_{0}}
$$

Where, $q_{e}$ and $c_{e}$ are absorption amount $(\mu \mathrm{g} / \mathrm{g})$ and concentration of $\mathrm{Tl}(\mu \mathrm{g} / \mathrm{L})$ at adsorption equilibrium respectively, and $q_{0}$ and $\mathrm{b}$ represent the maximum adsorption capacity of adsorbents $(\mu \mathrm{g} / \mathrm{g})$ and the Langmuir adsorption constant $(\mathrm{L} / \mu \mathrm{g})$, respectively. The values of $q_{0}$ and $\mathrm{b}$ can be calculated from the slope and intercept of the linear plot of $\mathrm{c}_{\mathrm{e}} / \mathrm{q}_{\mathrm{e}}$ against $c_{e}$ (Fig. 7).

Freundlich adsorption isotherm model

Freundlich isotherm model is used to describe the adsorption behavior that occurs on the heterogeneous surface[35]. The expression for Freundlich isotherm model is described in the following form:

$\ln q_{e}=\ln K_{F}+1 / n c_{e}$ concentration of $\mathrm{Tl}(\mu \mathrm{g} / \mathrm{L})$ at adsorption equilibrium respectively, $\mathrm{K}_{\mathrm{F}}$ is Freundlich isotherm constant, $\mathrm{n}$ is another constant in Freundlich isotherm model to indicate how favorable the adsorption progress. If the value of $1 / n$ is between 0 and 1 , which indicated that the adsorption process is in favor of the reaction conditions; If the value of $1 / n$ greater than 1 , it is un-favorable; If the value of $1 / n$ is approximately equal to 1 then the process is homogeneous[36]. $\mathrm{K}_{\mathrm{F}}$ and $\mathrm{n}$ can be obtained from the intercept and the slope of the linear plot of $\ln q_{e}$ versus $\ln c_{e}$ (Fig. 7).

The adsorption parameters are listed in Table 1. It is obviously that the correlation coefficient $\left(\mathrm{R}^{2}\right)$ of Langmuir isotherm model is much higher than that of Freundlich isotherm model, which indicates that the Langmuir model describes the adsorption process better. Furthermore, the adsorption of $\mathrm{Tl}$ is homogeneous. After the adsorbate is adsorbed on the surface of the adsorbent, the adsorbate has no interaction with each other. At the same time, the adsorption process is not affected by the adsorption capacity. The adsorption mechanism of Tl by the resin is that $\mathrm{Tl}$ can be exchanged with cations in the resin. Due to the unique structural characteristics of the resin, large exchangeable space spacing, there is no interaction between $\mathrm{Tl}$ ions after exchange. Meanwhile, the maximum adsorption capacity of $\mathrm{Tl}$ is lower than the maximum exchangeable amount of resin, which is consistent with the basic assumptions in the Langmuir adsorption model[37].

Where, $q_{e}$ and $c_{e}$ are absorption amount $(\mu \mathrm{g} / \mathrm{g})$ and

Table 1 The adsorption parameters according to Langmuir and Freundlich adsorption isotherm model

\begin{tabular}{cccc}
\hline Adsorption isotherm models & $\mathrm{R}^{2}$ & Model parameters & Linear equation \\
\hline Langmuir & 0.9688 & $q_{0}=636.94 \mu \mathrm{g} / \mathrm{L} ;$ & $\frac{c_{e}}{q_{e}}=0.15214+0.00157 c_{e}$ \\
& & $\mathrm{~b}=0.01032$ & $1 / n=0.00848 ;$ \\
Freundlich & 0.8888 & $\ln \mathrm{K}_{\mathrm{F}}=4.56771$ & $\ln q_{e}=4.56771+0.00848 c_{e}$ \\
& & & \\
\hline
\end{tabular}




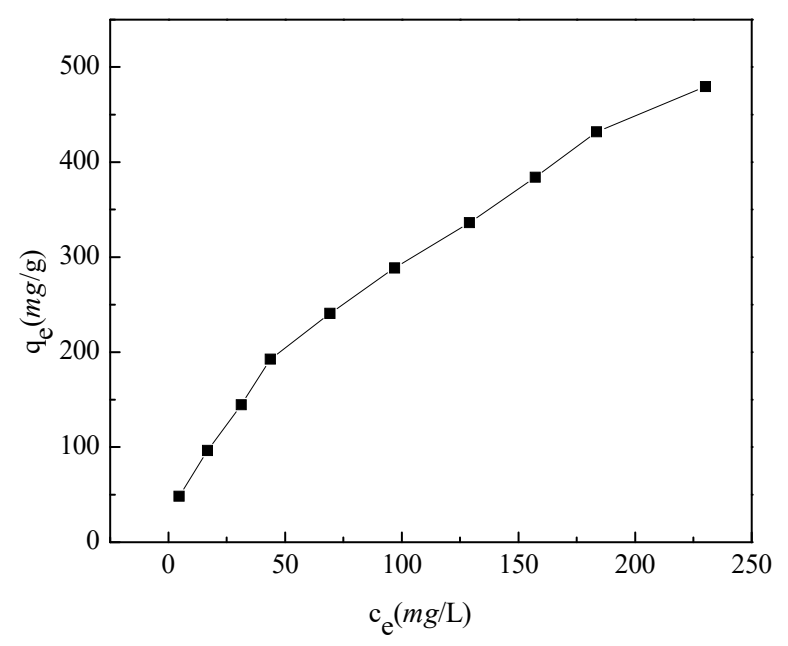

Fig. 6 Resin adsorption $\mathrm{Tl}$ adsorption isotherms

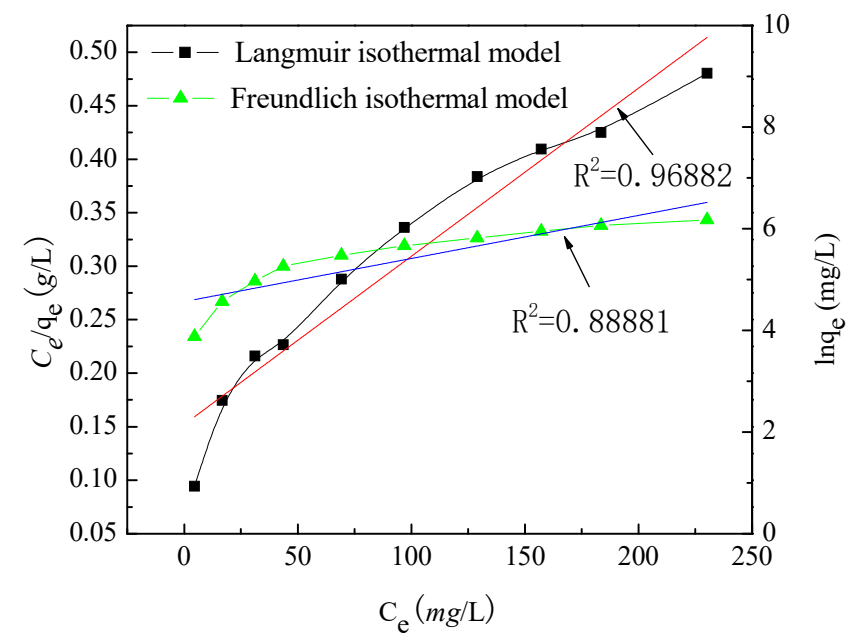

Fig. 7 Linear fitting of Langmuir and Freundlich isotherm models

\subsection{Desorption tests}

The raw water $(12133.64 \mu \mathrm{g} / \mathrm{L}, 2 \mathrm{~L})$ was adsorbed with $500 \mathrm{~g}$ chelating resin for $6 \mathrm{~h}$, and the concentration of $\mathrm{Tl}$ after adsorption is $43.62 \mu \mathrm{g} / \mathrm{L}$. Therefore, the amount of $\mathrm{Tl}$ adsorbed by the resin was $48.36 \mu \mathrm{g} / \mathrm{g}$.

\subsubsection{Effect of desorbent concentration}

$5 \%, 10 \%, 15 \%, 20 \%$ hydrochloric acid $(60 \mathrm{~mL})$ was added to 4 parts of the resin $(30 \mathrm{~g})$ after adsorbing raw water, and test the sample after shaking for $4 \mathrm{~h}$. The results were shown in Fig. 8 and Table 2. We can obviously see that the desorption effect is basically unchanged between $60 \%$ and $67 \%$. It may be that the resin adsorption does not reach saturation. Desorption process reached equilibrium state after added the desorbent, the desorption rate cannot be increased even if the desorbent solution concentration is increased. Excessive concentration of the desorbent solution may destroy the structure of the resin, decrease the adsorption capacity and difficult to cleaning and operating. Therefore, the optimum desorbent concentration in the subsequent static desorption is $5 \%$.

Table 2 Effect of desorbent concentration on desorption rate

\begin{tabular}{cccc}
\hline $\begin{array}{c}\text { Tl content in resin } \\
(\mu \mathrm{g} / \mathrm{g})\end{array}$ & $\begin{array}{c}\text { The concentration of } \\
\text { desorbent }(\%)\end{array}$ & $\begin{array}{c}\text { Desorption content } \\
\text { of Tl }(\mu \mathrm{g})\end{array}$ & $\begin{array}{c}\text { Desorption rate } \\
(\%)\end{array}$ \\
\hline \multirow{2}{*}{483.6} & 5 & 964.64 & 66.49 \\
& 10 & 865.63 & 59.67 \\
\hline
\end{tabular}




\begin{tabular}{rcc}
\hline 15 & 947.21 & 65.29 \\
20 & 948.85 & 65.40 \\
\hline
\end{tabular}

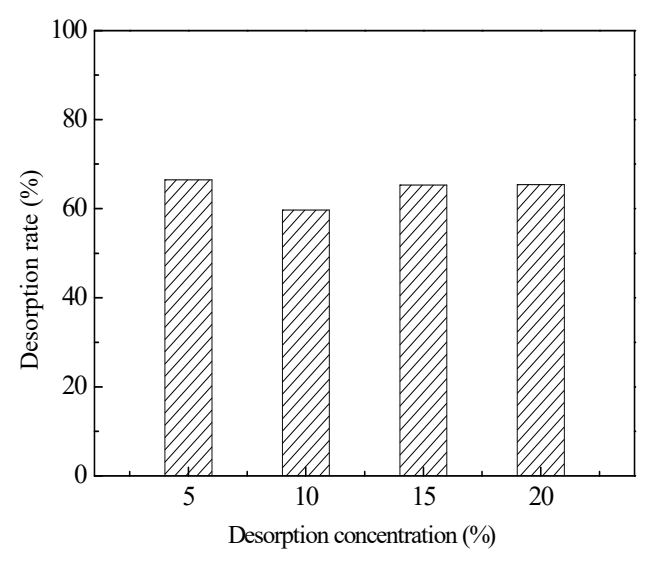

Fig. 8 Effect of desorption concentration on desorption rate

\subsubsection{Effect of solid-liquid ratio of adsorbent and desorbent}

$30,60,90,120 \mathrm{~mL}$ hydrochloric acid $(5 \%)$ was added to 4 parts of the resin $(30 \mathrm{~g})$ after adsorbing raw water, and determined the sample after shaking for $4 \mathrm{~h}$. Results were shown in Fig. 9 and Table 3. As the liquid-solid ratio increased, the desorption rate of $\mathrm{Tl}$ in the resin increased from $50.09 \%$ to $81.72 \%$. The desorption process was promoted by the increase of the concentration difference between adsorbent and Tl. Therefore, the liquid-solid ratio should be increased as much as possible to make desorption more complete.

Table 3 Effect of solid-liquid ratio of adsorbent and desorbent on desorption

\begin{tabular}{cccc}
\hline $\begin{array}{c}\text { Tl content in resin } \\
(\mu \mathrm{g} / \mathrm{g})\end{array}$ & $\begin{array}{c}\text { Solid-liquid ratio of adsorbent } \\
\text { to desorbent }\end{array}$ & $\begin{array}{c}\text { Desorption content } \\
\text { of } \mathrm{Tl}(\mu \mathrm{g})\end{array}$ & $\begin{array}{c}\text { Desorption rate } \\
(\%)\end{array}$ \\
\hline $1: 1$ & 726.66 & 50.09 \\
& $1: 2$ & 943.88 & 65.06 \\
483.6 & $1: 3$ & 1128.50 & 77.78 \\
& $1: 4$ & 1185.63 & 81.72 \\
\hline
\end{tabular}

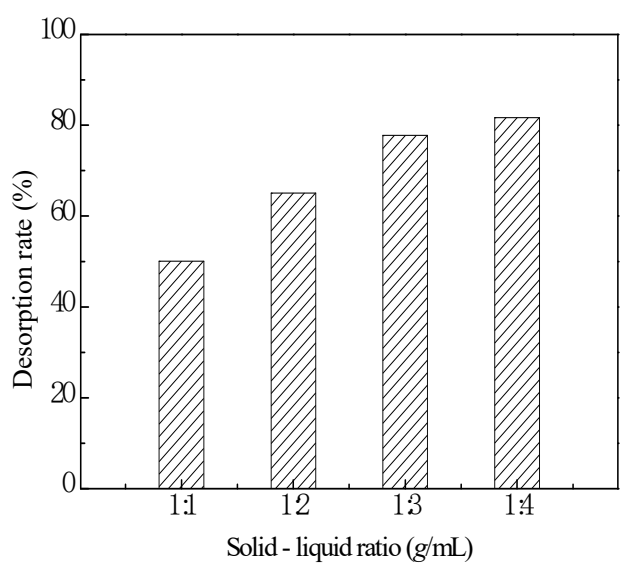

Fig. 9 Effect of solid-liquid ratio of adsorbent and desorbent on desorption 


\subsubsection{Effect of desorption time}

Added 5\% hydrochloric acid $(60 \mathrm{~mL})$ to the resin after the adsorption of raw water, and test the sample after shaking for $4,8,12,16,20 \mathrm{~h}$ respectively. The results were shown in Fig. 10 and table 4. As the desorption time is extended, the desorption rate is not significantly improved and remains at $64 \%-68 \%$. Since the desorption process reached equilibrium within $4 \mathrm{~h}$, there was no significant change in the desorption rate with the continued extension of the desorption time.

Table 4 Effect of desorption time on desorption

\begin{tabular}{cccc}
\hline $\begin{array}{c}\mathrm{Tl} \text { content in resin } \\
(\mu \mathrm{g} / \mathrm{g})\end{array}$ & $\begin{array}{c}\text { Desorption time } \\
(\mathrm{h})\end{array}$ & $\begin{array}{c}\text { Desorption content } \\
\text { of } \mathrm{Tl}(\mu \mathrm{g})\end{array}$ & $\begin{array}{c}\text { Desorption rate } \\
(\%)\end{array}$ \\
\hline 4 & 996.63 & 68.69 \\
& 8 & 929.22 & 64.05 \\
483.6 & & & \\
& 12 & 1000.49 & 68.96 \\
& 16 & 956.63 & 65.94 \\
& 20 & 948.91 & 65.41 \\
\hline
\end{tabular}

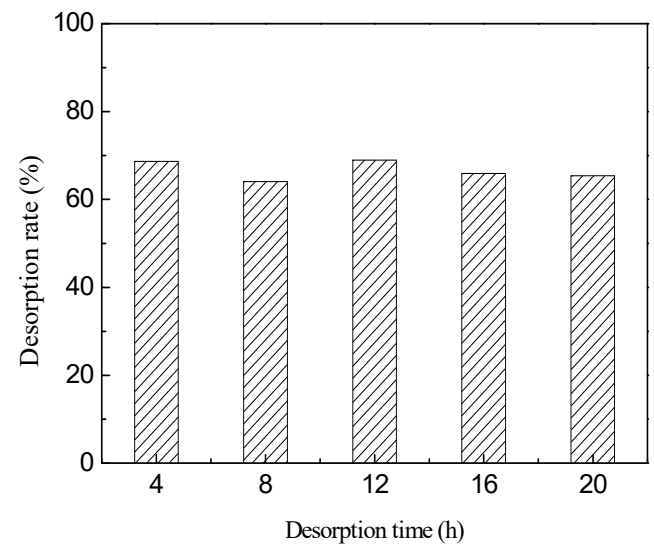

Fig. 10 Effect of desorption time on desorption

\subsection{Resin regeneration properties study}

Regeneration is an vital factor to assess the application performance of the adsorbent[38]. In order to investigate the regenerative properties of the resin, this paper studied the re-adsorption of used resin treated with hydrochloric acid on Tl-containing wastewater. The relationship between the times of adsorptions and the adsorption capacity and adsorption rate of the resin for Tl were shown in Fig. 11. It is found that the adsorption capacity and efficiency of the resin after repeated use for 6 times were still $612.6 \mu \mathrm{g} / \mathrm{g}$ and $95.8 \%$ respectively, indicating that the resin have good regenerability.

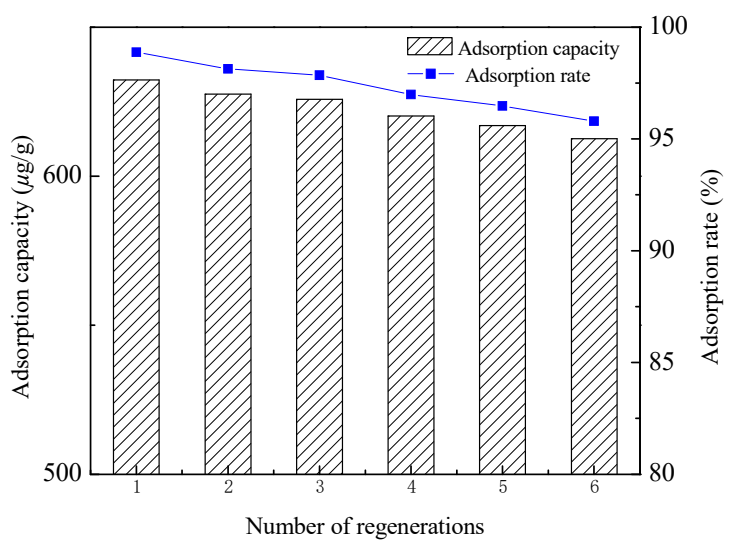

Fig. 11 The relationship between the number of regeneration and the adsorption capacity and adsorption rate 


\subsection{Dynamic adsorption study}

Dynamic adsorption curve of chelating resin on Tlcontaining wastewater were shown in Fig. 12. When the adsorption time is $25 \mathrm{~h}$, the concentration of $\mathrm{Tl}$ in the effluent from the adsorption column is exactly the same as the concentration of $\mathrm{Tl}$ in the original solution. At this point we can conclude that the adsorption of the resin has reached dynamic saturation. The amount of saturated adsorption can be calculated by the following formula: $q=\int_{0}^{t} Q\left(C_{0}-C_{t}\right) d t=Q C_{0} t-\int_{0}^{t} Q C_{t} d t \quad(3-7)$
Where, $\mathrm{C}_{0}$ is the inlet concentration, $\mathrm{C}_{\mathrm{t}}$ is the outlet concentration at $\mathrm{t} \mathrm{h}, \mathrm{Q}$ is wastewater flow, and the $\int_{0}^{t} Q C_{t} d t$ is the area under the penetration curve when $\mathrm{t} h$. It can be seen from the calculation that the cumulative adsorption capacity at the time of dynamic adsorption saturation $(621.4 \mu \mathrm{g} / \mathrm{g})$ is slightly lower than that at the static adsorption saturation $(636.94 \mu \mathrm{g} / \mathrm{g})$. Because of the adsorption heat and dynamic equilibrium, the temperature of the dynamic adsorption may rise, so the amount of dynamic adsorption is lower than that of static adsorption.

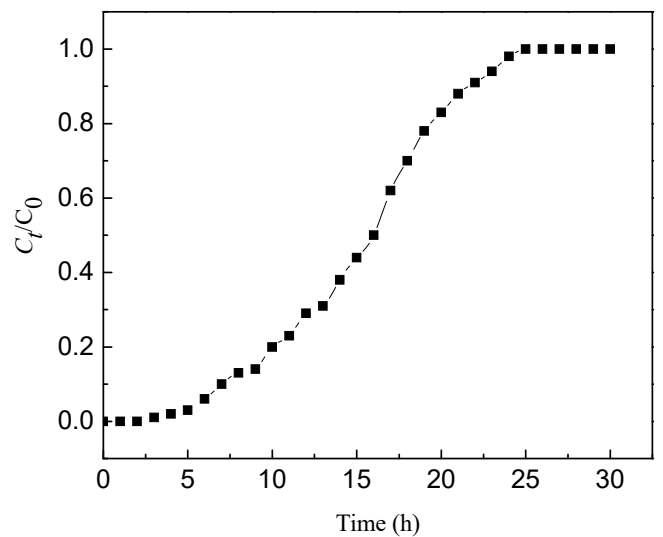

Fig. 12 The dynamic adsorption curve of resin on $\mathrm{Tl}$

\section{Conclusions}

Based on the previous research on the treatment of Tlcontaining wastewater, this work aims to optimize the process parameters by measuring the effects of $\mathrm{pH}$, temperature, initial concentration of $\mathrm{Tl}$ and adsorption time on the adsorption performance of the resin. We can draw the following conclusions: The optimum $\mathrm{pH}$ and temperature of the adsorption process are 9 and $30^{\circ} \mathrm{C}$; respectively.; the adsorption kinetics study shows that the adsorption of resin can reach the adsorption equilibrium at $80 \mathrm{~min}$ and consistent with the second-order kinetic

\section{Acknowledgements}

The study was financially supported by Specialized Innovation and Development of Provincial Scientific Research Institutions in Hunan Province: Development and Demonstration of Typical Heavy Metal High Polymer Compound Flocculant and Its Process Development

\section{References}

1. Zhang C, Lai C, Zeng G, Huang D, Yang C, Wang Y, Zhou Y and Cheng M. Water Research, 95 , 103112(2016)

2. Hirsch R, Ternes $\mathrm{T}$, Haberer $\mathrm{K}$ and Kratz K-L. Science of The Total Environment, 225 , 109118(1999) adsorption model; the maximum adsorption capacity of the resin on $\mathrm{Tl}$ is $636.94 \mu \mathrm{g} / \mathrm{g}$; the adsorption is better described by Langmuir isotherm model. After six reused cycles, the adsorption efficiency of resin on $\mathrm{Tl}$ was still at a high level $(95.8 \%)$. This work could not only help us understand how the factors influence the adsorption behavior of resin onto $\mathrm{Tl}$ and determine the optimization process parameters, but also could provide a strong basis for the removal of heavy metals from wastewater.

(2013TF1008), Hunan key research and development plan project: Research and development of technology and equipment related to heavy acid and mud resources (S2017SYSF0217).

3. Xiong Y, Strunk P J, Xia H, Zhu X and Karlsson H T. Water Research, 35, 4226-4230(2001)

4. Pandimurugan $\mathrm{R}$ and Thambidurai. Journal of Environmental Chemical Engineering, 4, 13321347(2016)

5. Tang L, Wang J-j, Wang L, Jia C-t, Lv G-x, Liu N 
and Wu M-h. ACS Sustainable Chemistry \& Engineering, 4, 4617-4625(2016)

6. Zeng G, Wan J, Huang D, Hu L, Huang C, Cheng M, Xue W, Gong X, Wang R and Jiang D. Journal of hazardous materials , 339, 354-367(2017)

7. Gupta V K, Rastogi A and Nayak A .Journal of Colloid and Interface Science, 342, 135-141(2010)

8. Zhang G, Fan F, Li X, Qi J and Chen Y. Chemical Engineering Journal, 331, 471-479(2018)

9. Rickwood C J, King M and Huntsman-Mapila P. Ecotoxicology and Environmental Safety, 115, 300308(2015)

10. Turner A and Furniss O. Marine Pollution Bulletin , 64, 2720-2724(2012)

11. Cvjetko P, Cvjetko I and Pavlica M. Arhiv za higijenu rada i toksikologiju, 61, 111-119(2010)

12. U. Borgmann V C, W.P. Norwood, J. Lechner. Environmental Pollution, 99, 105-114(1998)

13. Keith L H and Telliard W A. Environmental Science and Technology, 13, 416-423(1979)

14. Delgado G E, Mora A J, Pérez F V and González J. Physica B: Condensed Matter, 391, 385-388(2007)

15. Khlybov E P, Kostyleva I E, Nizhankovskii V I, Palewski T, Warchulska J and Nenkov K. Physica B: Condensed Matter, 294-295, 367-370(2001)

16. Prytulak J, Nielsen S G, Plank T, Barker $M$ and Elliott T. Chemical Geology, 345, 139-149(2013)

17. Karunakaran C, Kalaivani S, Vinayagamoorthy $P$ and Dash S. Materials Science in Semiconductor Processing, 21, 122-131(2014)

18. $\mathrm{Xu}$ Youze, Cheng Yingxiang, Fu Guangyi, Zhao Yuanyuan ,Chen Caili. Environmental Protection of Chemical Industry, 37, 62-67(2017)

19. LU Shao-ming, ZHAO Tian-tia,n MENG Jian-bin. WATER PURIFICATION TECHNOLOGY. 27, 25 27(2008)

20. Karatepe A, Soylak M and Elçi L. Talanta, 85, 19741979(2011)

21. Amin A S, El-Sharjawy A-A M and Kassem M A. Spectrochimica Acta Part A: Molecular and Biomolecular Spectroscopy, 110, 262-268(2013)

22. Luo Jinxin. MODERN SCIENTIFIC
INSTRUMENTS. 39-41(2000)

23. Cao lei, $\mathrm{Xu}$ xiajun. Fujian Analysis \& Testing, $27-$ 29(2012)

24. Chakravarty $\mathrm{R}$ and Banerjee $\mathrm{P}$ C. Bioresource Technology, 108, 176-183(2012)

25. Deng $\mathrm{S}$ and Ting Y-P . Water Research, 39, $2167-$ 2177(2005)

26. Huang J, Ye M, Qu Y, Chu L, Chen R, He Q and Xu D. Journal of Colloid and Interface Science, 385, 137-146(2012)

27. Namasivayam $\mathrm{C}$ and Yamuna $\mathrm{R} \mathrm{T}$. Chemosphere, 30, 561-578(1995)

28. Aharoni C, Levinson S, Ravina I and L. Sparks D. Soil Science Society of America Journal, 55, 1307(1991)

29. ZENG De-fang, LI Juan, FAN Lin, YUAN Ji-zu. JOURNAL OF CHINA UNIVERSITY OF MINING \& TECHNOLOGY, 34, 374-377(2005)

30. Periasamy $\mathrm{K}$ and Namasivayam C. Industrial \& Engineering Chemistry Research, 33, 317-320(1994)

31. Powell T, Brion G M, Jagtoyen M and Derbyshire F. Adsorption Environmental Science \& Technology, 34, 2779-2783(2000)

32. LI Huawei, ZHENG Shourong, XU Zhaoyi, SHAO Fei. ION EXCHANGE AND ADSORPTION, 23, 408-414(2007)

33. Huang T, Yan M, He K, Huang Z, Zeng G, Chen A, Peng M, Li H, Yuan L and Chen G. J Colloid Interface Sci, 543, 43-51(2019)

34. Luo S, Xu X, Zhou G, Liu C, Tang Y and Liu Y. Journal of hazardous materials, 274, 145-155(2014)

35. Nandi B K, Goswami A and Purkait M K. Journal of hazardous materials, 161, 387-395(2009)

36. Rauf M A, Bukallah S B, Hamour F A and Nasir A S. Chemical Engineering Journal, 137, 238-243(2008)

37. Ma Hongmei, Zhu Zhiliang, Zhang Ronghua, Lin Jianwei, Zhao Jianfu. ION EXCHANGE AND ADSORPTION, 22, 519-526(2006)

38. Peng M, Chen G, Zeng G, Chen A, He K, Huang Z, $\mathrm{Hu}$ L, Shi J, Li H, Yuan L and Huang T. Applied Clay Science, 163, 63-71(2018) 